\title{
Working Mechanism of a High-performance Tower Crane Attached to Wall Joints
}

\author{
Gang Yao ${ }^{1,2}$, Chengcheng $\mathrm{Xu}^{1,2}$, Yang Yang ${ }^{1,2, *}$, Mingpu Wang ${ }^{1,2}$, Mao Zhang $^{3}$ and Ayad Thabeet ${ }^{4}$ \\ ${ }^{1}$ Key Laboratory of New Technology for Construction of Cities in Mountain Area, Ministry of Education, Chongqing 400040, China \\ ${ }^{2}$ School of Civil Engineering, Chongqing University, Chongqing 400040, China \\ ${ }^{3}$ China Construction Second Engineering Bureau Ltd, Beijing 100000, China \\ ${ }^{4}$ Technical University of Kosice, Slovak 999037, Slovak Republic
}

Received 19 October 2017; Accepted 15 December 2017

\begin{abstract}
The tower cranes widely used in the construction of super high-rise buildings are a multi-degree-of-freedom system located at the top of building structures. Loads, such as self-weight and hoisting loads, are all borne by the embedded crane tower parts attached to the wall joints of towers and thus the safety of these parts is crucially important. To reveal the working mechanism of the attached to the wall joints of high-performance tower cranes, a method for analyzing the force performance of the joints was proposed. First, a pullout test was conducted by setting the embedded parts of the scale model with different parameters. Then, the finite element models of specimens were created for the simulation of factors influencing the damage mechanism and anchor capacity of the wall joints. Finally, the credibility of the model test data and the rationality of the finite element models were verified through comparative analysis. Results show that the embedded parts of the wall joints undergo two types of damage depending on the installation form: the pull out damage of parts due to incomplete anchoring (ultimate capacity of $256.67 \mathrm{kN}$ ), and the bending fracture damage of shear wall under sufficient anchoring (ultimate capacity of $463.33 \mathrm{kN}$ ). A large difference is noted between the bearing capacities of the two types. The load-displacement curves for the embedded parts exhibit evident two-stage variation, whereas the effect of anchoring reinforcement mode on displacement is unapparent. This study provides references for the working mechanism analysis and performance evaluation of the attached to the wall joints of high-performance tower cranes.
\end{abstract}

Keywords: Jib crane, Attached to the wall joint, Damage mechanism, Embedded part installation

\section{Introduction}

Height records of skyscrapers in China are reviewed constantly every year. Uniquely shaped super high-rise buildings that have attracted attention worldwide, such as the 492 m-tall Shanghai World Financial Center, the $610 \mathrm{~m}$ tall Guangzhou Television Tower, the $432 \mathrm{~m}$-tall Zhujiang New Town West Tower, the $357 \mathrm{~m}$-tall Chongqing World Financial Center, the $330 \mathrm{~m}$-tall China World Trade Center Tower III, and the $234 \mathrm{~m}$-tall New China Central Television Tower(CCTV), have been completed one after another. During the construction of these skyscrapers with steel and concrete as the main structural materials, jib cranes exert its unique advantages, whose safety has drawn widespread attention accordingly [1].

At present, many countries expressly stipulate in the building law that hoisting operations cannot go beyond the site of construction works; that is the jib cannot exceed the construction fences [2, 3]. In addition, although the traditional horizontal arm tower machine is more inexpensive than the jib crane at the same tonnage and lifting torque and also has a higher luffing speed when lifting heavy objects, it can hardly meet the construction requirements of today's super high-rise buildings. To be specific, first, construction sites are small in area, especially those in the downtown areas, which limit the use of

\footnotetext{
*E-mail address: yy20052710@163.com

ISSN: 1791-2377 @ 2018. Eastern Macedonia and Thrace Institute of Technology. All rights reserved.

doi:10.25103/iestr.111.03
}

horizontal arm tower machine. Second, today's super highrise buildings generally use concrete-filled steel tubes, steel beams, and built-in steels. Moreover, steel structures and embedded parts at the joints are heavy, with a single piece even exceeding $40 \mathrm{t}$, so the lifting capacity and lifting torque of the horizontal arm tower machine can hardly meet up the standards. Meanwhile, to improve efficiency and shorten duration, multiple tower cranes are now used simultaneously. Compared to the horizontal arm tower machine, the jib crane has obvious advantages, such as large lifting capacity and lifting torque. For example, the M900D jib crane features a maximum lifting capacity of over $60 \mathrm{t}$ and a maximum lifting torque of over $900 \mathrm{tm}$ and prevents the mutual interference produced by simultaneous operation of multiple tower cranes. In addition, it has good safety and equilibrium stability in non-operating state, especially during windy weather conditions [4].

Owing to the development trends in the construction industry, the size of construction floorage has decreased. The use of jib crane in skyscraper construction in crowded cities can meet the construction requirements, so its application is expected to increase. This type of construction is the key for on-site operations of skyscraper construction. Various stages of construction and different types of work all require the assistance of tower cranes. In high-intensity earthquake-prone areas, tower cranes may be subjected to seismic action during construction $[5,6]$. The safety of tower cranes has therefore become a core factor in the construction safety of super high-rise buildings. Moreover, the tower crane structure is a multi-degree-of-freedom (DOF) 
system, which is located at the top of building structures. Its self-weight, hoisting load, and other work loads are all borne by the embedded parts and attached to the wall joints of towers, and its loads are still ultimately transferred to the main structure of super high-rise buildings from the embedded parts attached to the wall joints. Therefore, the safety of attached to the wall joints of tower crane is crucially important [7]. Thus, the influence of the force actions of these joints on safety performance must be determined on the basis of the working mechanisms of these joints.

In view of this, the force performance of attached to the wall joints of high-performance jib cranes, was investigated through scale model test and numerical simulation in this study. A pullout test was carried out by setting the embedded part of the scale model with different parameters, and the whole process of model test was numerically simulated by finite element method for the comparative analysis of test results. The purpose of this study was to analyze the influencing factors of anchor capacity, damage mechanism, and influence degree of various parameters for the attached to the wall joints of the tower crane and to analyze the force performance of the joints and the working mechanism for enhancing their seismic performance.

\section{State of the art}

Tower cranes are typically attached to the core tubes of super high-rise building. When subjected to seismic action during construction, tower crane parts attached to wall joints undergo considerable dynamic magnification because of the obvious whiplash effect, and this condition decreases reliability [8]. At present, many studies on the auto-dynamic properties of tower cranes, safety factors, and dynamic responses under seismic action have been conducted. Tam Vivian W. Y. [1] analyzed the primary factors affecting the safe operation of tower cranes from the aspects of operators and operating methods and discussed proposals for the improvement of the safety performance of tower cranes. Aviad Shapira F. Asce [3] compiled multiple factors affecting the environmental safety of tower cranes on the basis of the experience and expertise of a number of senior safety and equipment managers in construction companies. The researchers analyzed the safety factors affecting the tower crane externally on the whole but failed to study or analyze the structural forces. By building Tower Crane (TC)option, supporting design flow, and related databases, Sohn Hyo Won [2] proposed a method for optimizing economic feasibility under promotion and stability conditions. Mara and T. G. [4] conducted wind tunnel tests to examine the effects of tower crane solid ratio and location on the overall wind load of building crane system. Their study provided a reference for the safety properties at tower crane support connections under wind loads, but they failed to consider the influence of wind loads on stresses and deformations at support connections. Li Yunling [5] claimed the necessity of dynamic analysis on tower cranes under seismic action and pinpointed the key factors based on the damage characteristics of tower cranes. However, he did not analyze the damage in wall joints in detail. Shen Tong [6] calculated the optimal parameters of Tuned Mass Damper (TMD) by Sadek method and compared the damping effects between different schemes. They found that the bidirectional TMD installed at the top of a tower can effectively control the seismic response of the tower crane, while having limited effect on their attached to the wall joints. Ai, Bing, Yang [9], and Huang Li Jeng [10] used the finite element model three-dimensional beam elements to establish vertical support column, horizontal cantilever loading arm, and bar element of tensile rebar concerning the analysis of free vibration and seismic response of typical tower crane frame structure. Although they found that the natural frequencies of typical tower cranes were generally lower than those of main buildings, they did not analyze the frequency of connection joint between the two in depth. Alamoreanu Mircea [11] and Li JR [12] computationally analyzed the displacements, velocities, and accelerations of the tower typical joints by considering that the saddle arm had a simplifying assumption in the direction of seismic wave propagation and put forward a three-DOF dynamical model, which failed to take into account the deformation of attached to the wall joints of the tower cranes. Shapira [13] calculated the life cycle of tower cranes but did not consider the overall stability or force-induced deformation. Dong[14] determined fatigue dangerous cross sections and critical points of jib structures by remanufacturing information of truck crane, and established the first principal stress-time history simulation model for critical points. Hazriq Izzuan Jaafara [15] analyzed the dynamic characteristics of cranes and adopted the dynamic model derived from Lagrange's equation to test various system parameters and to observe the actual behavior of the dynamic model system and deduce the nonlinear differential equation of the system. However, the dynamic model had a limited ability in analyzing the wall joints of tower cranes. Feng Ju [16] analyzed the modal characteristics and dynamic response of tower cranes using the finite element method. The researchers derived a parametric superelement formula for modeling multi-pulley cables in crane systems based on the frictionless pulley assumption but failed to simulate the connection of the tower crane itself to the main body. Moreover, studies on the wall joints of high-performance tower cranes are rare. The strength of these wall joints is not only related to crane safety properties and project progress but also associated with the safety of tower crane operators and should thus be given adequate attention.

The findings presented above focused mainly on the dynamic characteristics of tower cranes, safety factors, and dynamic responses of tower cranes under seismic action, whereas the performance of wall joints of tower cranes is seldom studied. Basing on existing studies, we used the scale model test and performed numerical simulations to explore the force performance of the wall joints of highperformance jib cranes. By setting the embedded parts of the scale model with different parameters, a pullout test was conducted, and the test results were comparatively analyzed. Factors, such as anchor capacity, damage mechanism, and influence degree of various parameters, that affects the wall joints of high-performance and ordinary tower cranes were studied. Meanwhile, the entire process of the model test was numerically simulated by the finite element method. Through a comparative analysis, the credibility of the model test data and the rationality of finite element models were mutually verified. Afterward, the research results were further extended based on the verified finite element models, and the force performance of attached to the wall joints of high-performance tower cranes, as well as the working mechanism for enhancing their seismic resistance, was analyzed.

The remainder of this study is organized as follows. Section 3 describes the static pullout test and finite element 
modeling. Section 4 analyzes the specimen test results, verifies the finite element model, and compares the model calculations with the test results. The last section summarizes the study and draws conclusions.

\section{Methodology}

\subsection{Test overview}

In the test, the scale model specimens were used and the loading protocol was created.

\subsubsection{Project background}

The Kunming Xishan Wanda Plaza project is an urban complex with a 66-storey south tower on the east side with a height of $307.8 \mathrm{~m}$. The south tower is arranged with three jib cranes (two ZSL1250 and one ZSL750), all of which are outer-hanging and inner-climbing tower cranes. In the present study, the joints of tower cranes used in engineering practice and the wall joints of high-performance tower cranes were taken as research objects. The parameter settings for the joint embedded parts are listed in Table 1, and the comparison between full-size pre-embedded parts and scaled embedded parts is shown in Fig. 1.

Table 1. Parameter settings for embedded parts

\begin{tabular}{|c|c|c|c|c|c|}
\hline \multirow[t]{2}{*}{ Specimen no. } & \multicolumn{2}{|c|}{$\begin{array}{c}\text { Anchor slab size } \\
(\mathrm{mm})\end{array}$} & \multicolumn{2}{|c|}{$\begin{array}{c}\text { Ending slab size } \\
(\mathrm{mm})\end{array}$} & \multirow[t]{2}{*}{ Peg setting } \\
\hline & b & h & b & h & \\
\hline 5 SJ204025N & 40 & 200 & 55 & 45 & No \\
\hline $6 \mathrm{SJ} 165000 \mathrm{~N}$ & 50 & 160 & \multirow{2}{*}{\multicolumn{2}{|c|}{$\begin{array}{l}\text { No ending slab } \\
\text { No ending slab }\end{array}$}} & No \\
\hline $7 \mathrm{SJ} 165000 \mathrm{Y}$ & 50 & 160 & & & Yes \\
\hline
\end{tabular}
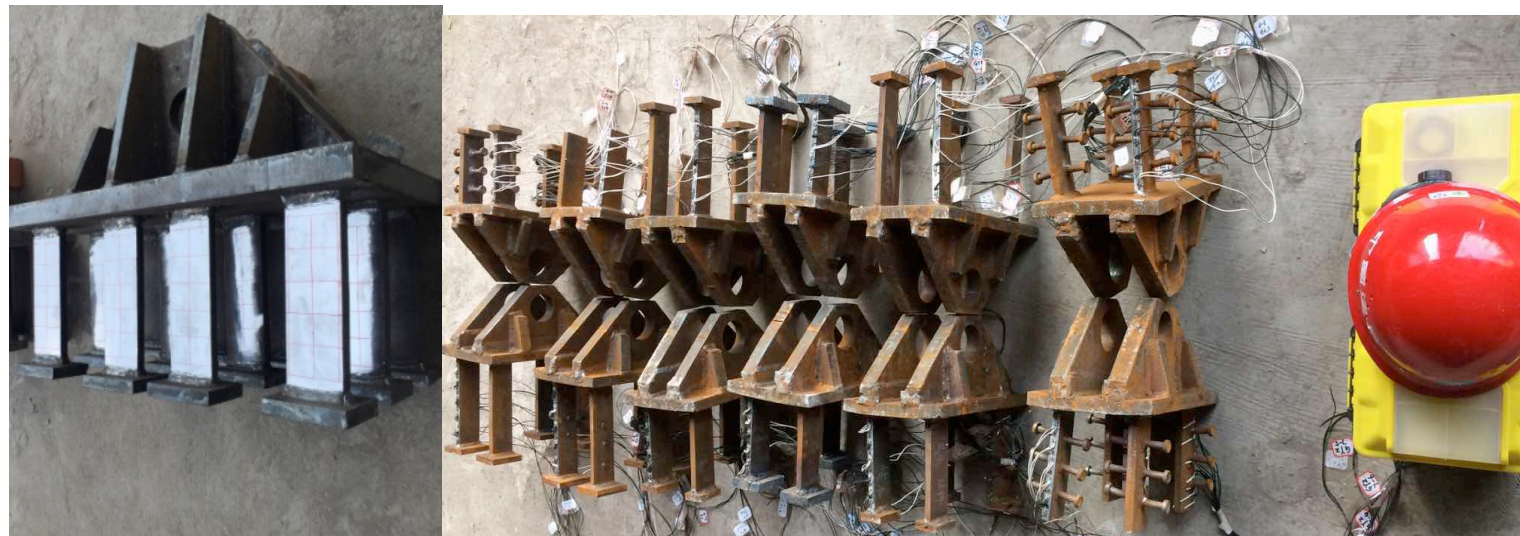

Fig. 1. Comparison between full-size pre-embedded parts and scaled embedded parts

\subsubsection{Specimen design and fabrication}

Jib cranes used in the construction of super high-rise buildings have heavy self-weight and large embedded parts. Their group anchor forms are often adopted, and the bearing capacities of their joints are strong. In laboratory conditions, full-size pre-embedded parts can hardly achieve monotonic static loading, which leads to structural damage. The scale model specimens with a scale ratio of 1:2 were used due to the limited research resource input and laboratory equipment conditions. Moreover, a single anchor slab was arranged separately at the four corners of embedded parts only. The embedded parts were fabricated according to the scale ratio using the actual construction site size as a reference. C30 concrete, grade 3 rebar, Q345C hot-rolled steel plate, similarity relations between model and prototype, and comparison of embedded parts are shown in Table 2.

Table 2. Similarity relations between model and prototype

\begin{tabular}{l|c|c|c|c}
\hline \multicolumn{2}{l|}{ Similar physical parameter } & Magnitude & Relational formula & Similarity relation \\
\hline 1 & Line length $/ L$ & $L$ & $S_{L}=L_{m} / L_{p}$ & $1 / 2$ \\
2 & Area / $A$ & $L^{2}$ & $S_{A}=S_{L}^{2}$ & $1 / 4$ \\
3 & Concentrated load / & $F$ & $S_{P}=P_{m} / P_{p}=S_{l}^{2} S_{\sigma}$ & $1 / 4$ \\
4 & Stiffness / $K$ & $F L^{-1}$ & $S_{K}=S_{E} / S_{L}$ & $1 / 2$ \\
5 & Displacement/x & $L$ & $S_{x}=S_{L}$ & $1 / 2$ \\
6 & Shear force/V & $F$ & $S_{V}=S_{E} S_{L}^{2}$ & $1 / 4$ \\
\hline
\end{tabular}

According to the Saint-Venant's Principle, the effect of local load influences the stress field distribution only within a certain range. After considering the economic efficiency and experimental rationality, the size of shear wall test surface was set three times the size of each side of the embedded part panel, whereas the thickness of the wall was set two times the minimum embedded depth of the embedded parts according to the actual embedded depth ratio. The wall reinforcement was installed according to the scale ratio with reference to the actual construction drawings and by using the same materials. The specimen fabrication was completed at the Chongqing Jiangbeizui International Finance Square (IFS) project office under the China Construction Second Engineering Bureau. The section and anchor slabs were set up, as shown in Fig. 2, whereas the experimental facility is shown in Fig. 3. 


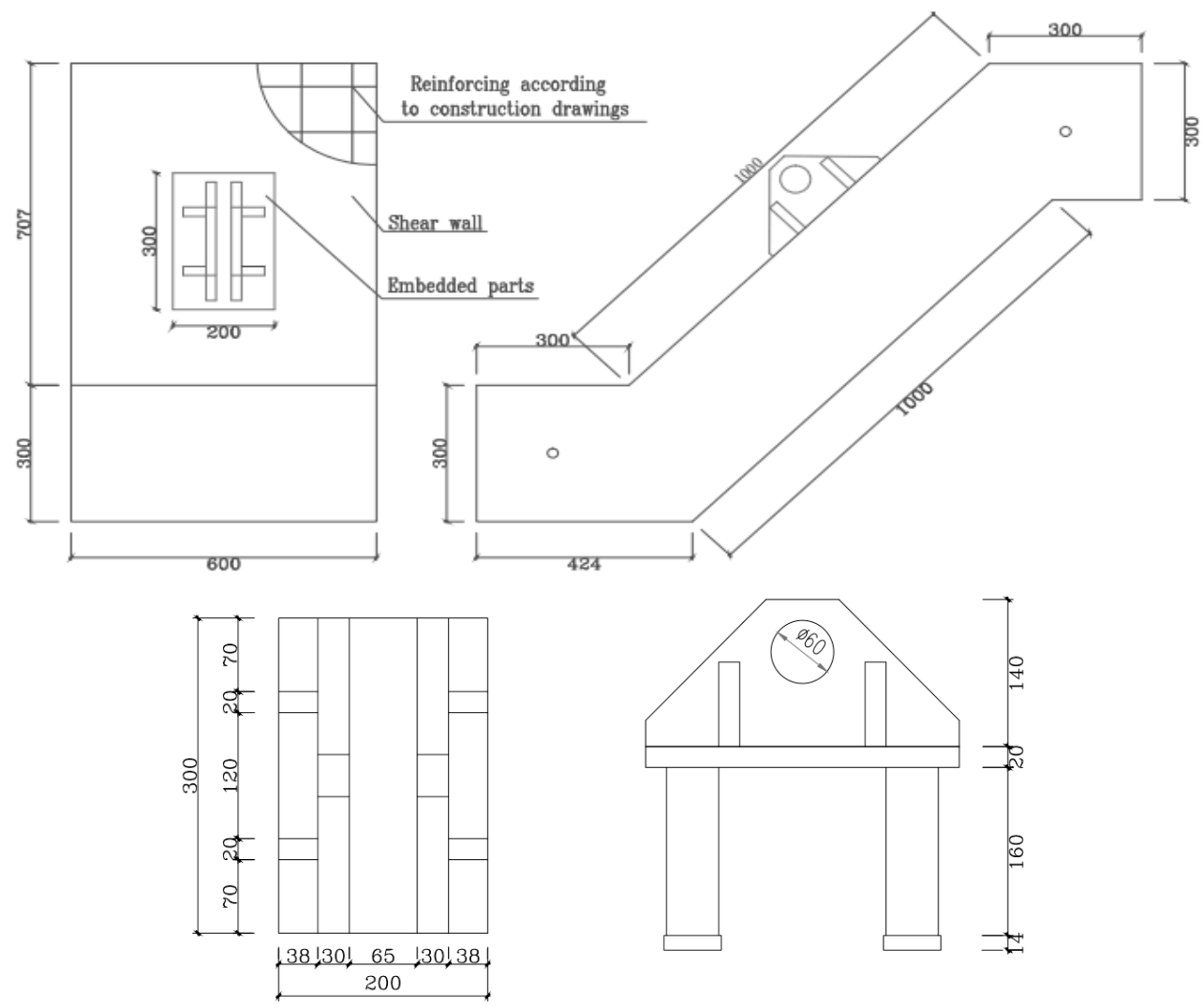

Fig. 2. Specimen construction drawings

\subsubsection{Experimental facility and loading protocol}

In the static pullout test, stepwise monotonic static loading was adopted. During the specimen installation, attention was paid to the geometric alignment. After alignment and setting out of the various test system components, they were calibrated and installed with laser level instrument to ensure that the jack center, embedded part centerline, and hinge center turning hinge midpoint were in the same vertical plane. Afterward, preloading was performed. The role of preloading is to check whether all test instrumentations are functioning properly and whether the facility is reliable. We can determine whether the relationship between load and deformation is stable and whether the specimen and the bearing are in good contact through the data collected from the preloading. Therefore, a preloading is necessary prior to formal loading, and the size of preload should be $20 \%$ of the theoretical ultimate load. Then, various instrumentations were adjusted to normal state and unloaded and zeroed before formal loading. Attention was paid to a few key joints, and the cracking point, yield point, limit point, and several drop points were captured. The differential was adjusted downward near the point locations, and each level of load was sustained for $1 \mathrm{~min}$. When the load started to decrease to disable loading continuance, the specimen could be considered to reach an ultimate carrying capacity and already entered the unloading phase. The data also need to be collected during the unloading phase. The experimental setup is shown in Fig. 3, whereas the monotonic stepwise loading is shown in Fig. 4.
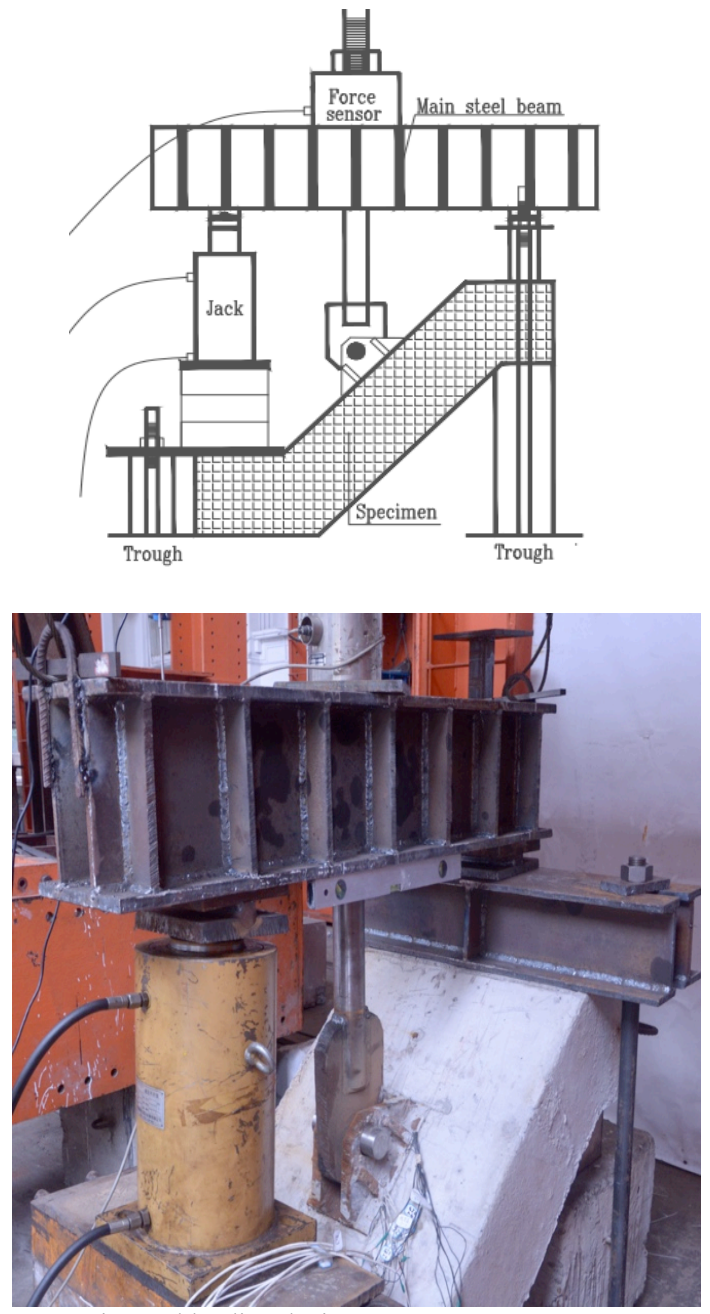

Fig. 3. Experimental loading device 


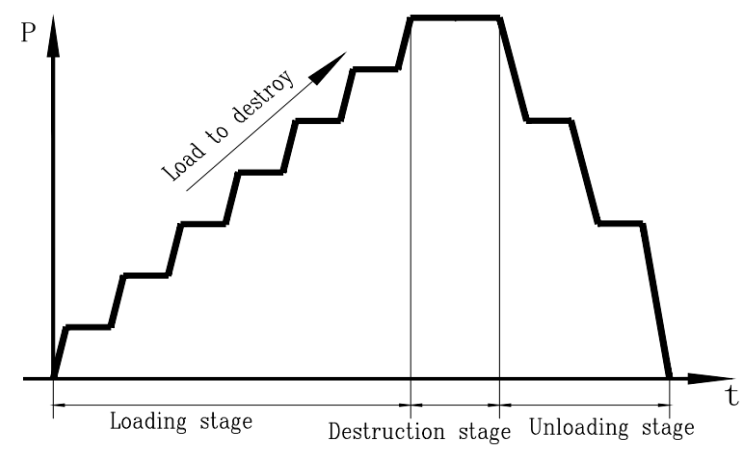

Fig. 4. Schematic of loading protocol.

\subsection{Finite element modeling}

The specimen parameters were assigned, and the same sectional size, ratio of reinforcement, and boundary conditions were set up. The finite element models of various components were built in the ABAQUS pre-processing program as shown in Fig. 5:

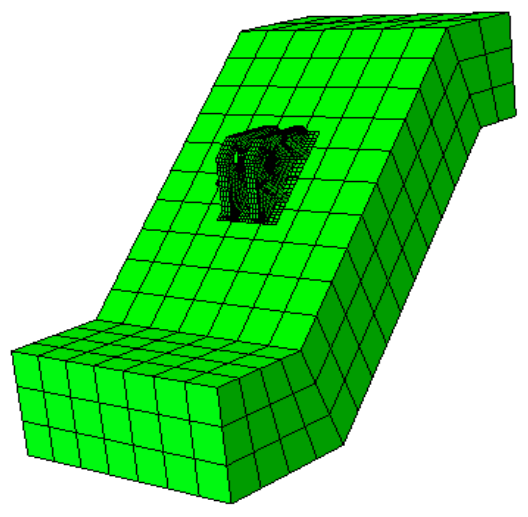

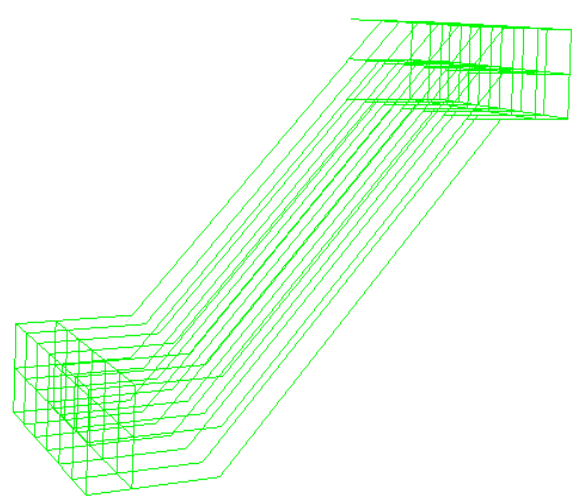

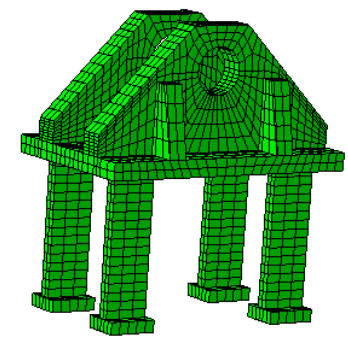

Fig. 5. Finite element models of the wall joints

\section{Result Analysis and Discussion}

\subsection{Test result analysis}

Ultimate pullout capacity value was confirmed and the loaddisplacement curves was got .

\subsubsection{Ultimate pullout capacity}

In the static pullout test of the attached to the wall joints of tower crane, the ultimate capacity of embedded parts was used to compare and check the safety. The ultimate capacities of the three specimens in the test are shown in Table 3.

Table 3. Ultimate capacities of specimens

\begin{tabular}{c|c|c|c|c|c}
\hline \multicolumn{2}{c|}{ Specimen no. } & $\begin{array}{c}\text { Cracking load } \\
\text { (KN) }\end{array}$ & $\begin{array}{c}\text { Ultimate capacity } \\
(\mathbf{K N})\end{array}$ & $\begin{array}{c}\text { Cracking/ultima } \\
\text { te }\end{array}$ & \multicolumn{1}{c}{ Damage pattern } \\
\hline 1 & SJ204025N & 143.5 & 463.33 & 0.31 & $\begin{array}{l}\text { Shear walls broke off along the major cracks, } \\
\text { and embedded parts were pulled out. }\end{array}$ \\
2 & SJ165000N & 99.2 & 256.67 & 0.39 & $\begin{array}{l}\text { Embedded parts slipped to pull out. } \\
\text { Shear walls broke off along the major cracks, } \\
3\end{array}$ \\
\hline
\end{tabular}

The comparison of ultimate capacity between specimens clearly showed that the cracking load of structure is approximately $30 \%-40 \%$ of the ultimate load. Moreover, the general trend is the greater the ultimate value, the larger the cracking load. Except for the blank control specimen SJ165000N, the remaining two specimens were both controlled by the flexural capacity of shear walls due to the same failure pattern and adequate anchorage.

\subsubsection{Load-displacement curves}

The changes in displacement varied between the high and low planes of the embedded parts. The displacements at two measuring points of each specimen under various levels of load were used to plot the scatter curves as shown in Fig. 6.

As shown in Fig. 6, the variation trends of increase in displacement with load were basically consistent, all of which were small in the former section and large in the latter section. The changes in the slope of curves showed that the curves were approximately steep before concrete cracking. Displacement changes were minimal at increased load, and the displacements of the upper and lower edges were close to each other. The differential of stepwise loading was not subdivided finely under the test conditions. Therefore, the stiffness degradation at the initiation of member cracking was not clearly observable in the curves. After cracking, the variation of displacement accelerated, and the slopes of curves began to drop as the load continued to increase, indicating that the stiffness of members degraded markedly after cracking. Moreover, the greater the load, the denser the fracture distribution, the larger the crack width, and the severer the stiffness degradation of members. When the ultimate load was approached, the load at a certain level of 
subdivision was sustained, yet the displacement remains continuously increased, and platform damage occurred. Afterward, the bearing capacity decreased, the descending sections appeared in the curves, and the structure underwent damage.
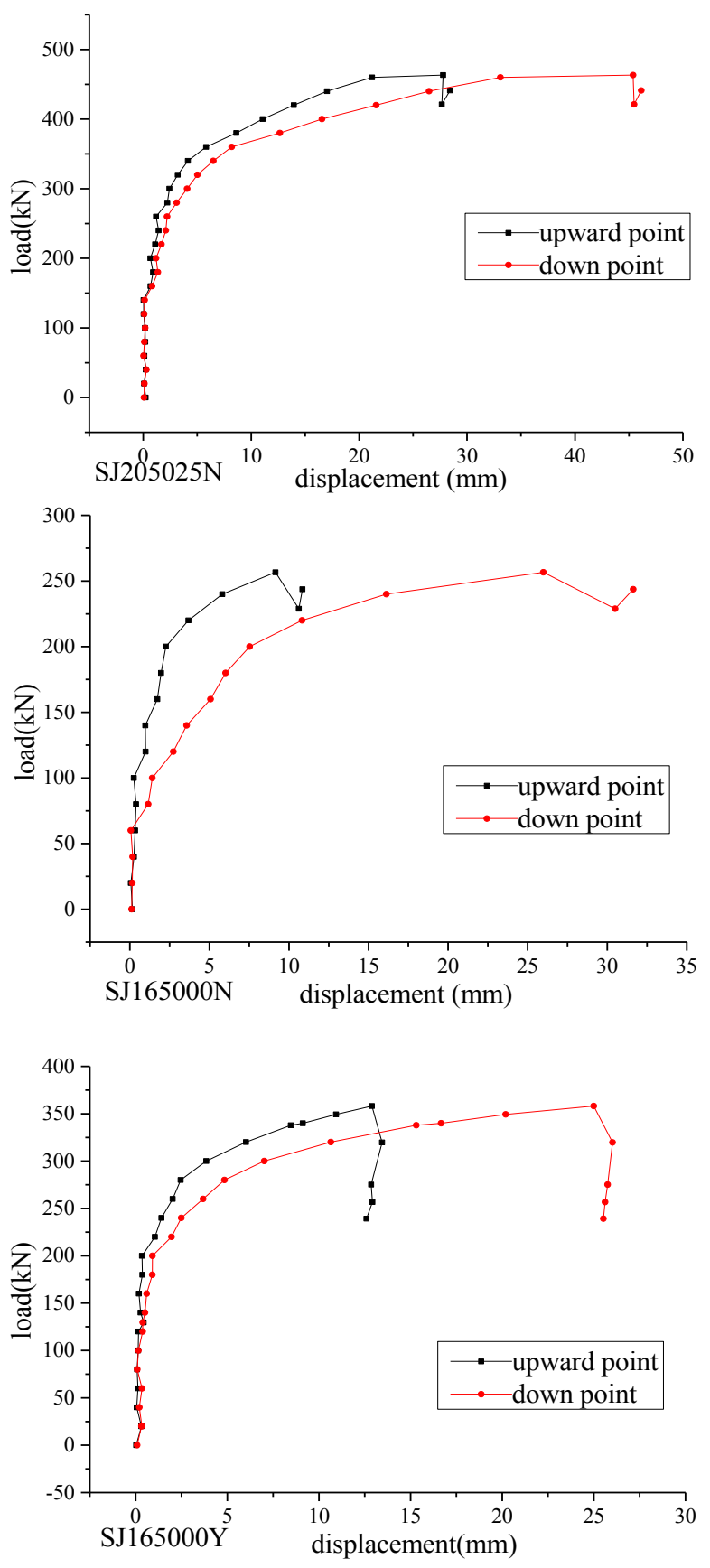

Fig.6. Load-displacement curves of specimens

\subsection{Finite element model verification}

The simulation calculations were extracted from the ABAQUS visualized post-processing module and compared with the test results of the corresponding specimens for mutual verification of the authenticity of the experimental data and the correctness of the finite element models. For the attached to the wall joints models of tower cranes that were loaded stepwise statically, the primary concern was the damage pattern and the ultimate capacity of the joints. The stress and displacement cloud diagrams of the specimens were compared, as shown in Figs. 7-9.
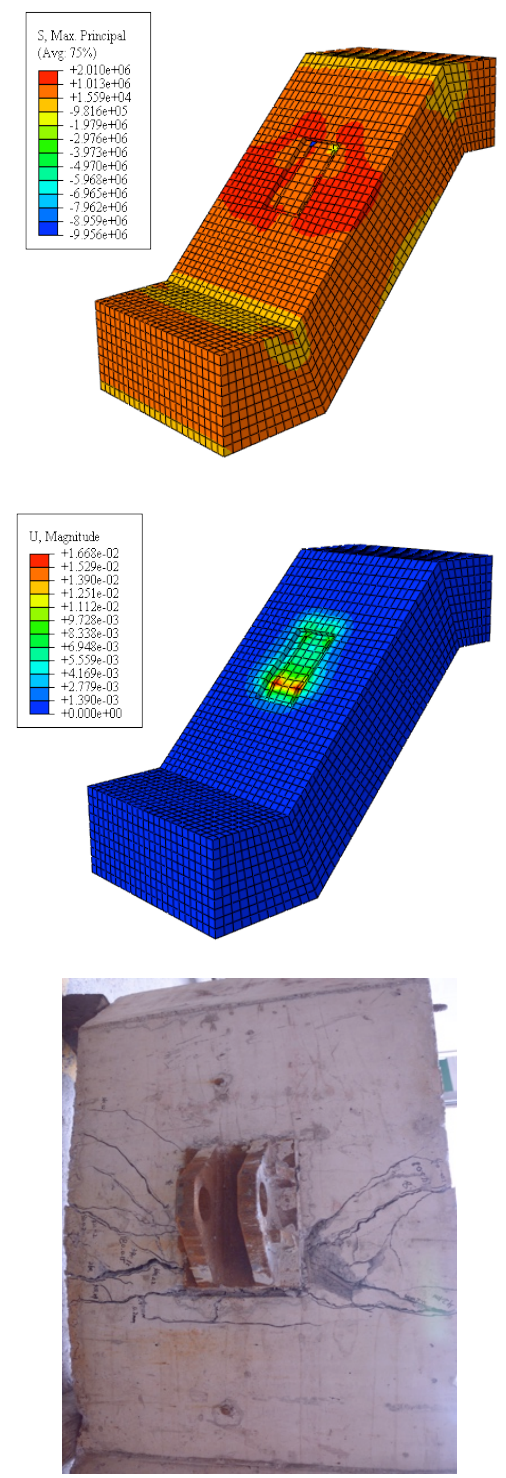

Fig.7. Comparative analysis diagrams for specimen SJ165025N

In ABAQUS, the solid elements were under bidirectional loading. The comparisons of the main stress cloud and main strain cloud show that the principal tensile stress at the lower part of shear wall was large during damage, which was extended to both sides of concrete members. As shown from the stress cloud of the embedded parts themselves, the stress of anchor slabs was smaller than their yield strength. Only elastic deformation occurred under the simulated external load, whereas the ending slabs did not deform obviously. This finding is in agreement with the test measurements. The stress cloud of specimen SJ165000N shows that the embedded part stress had a small influence range, the displacement was also only concentrated in the locations of four anchor slabs, and the bearing capacity was determined by the defined interface bonded slipping constitutive relation. For the remaining two specimens, the bearing capacity was controlled by the strength of concrete due to adequate anchorage. The principal stress concentration locations shown in the stress clouds corresponded to the locations of the initial cracking and major cracks of the test specimens, which were the concentrated damage locations of members. The comparison results between the simulated and tested bearing capacity values of specimens are listed in Table 4 . 

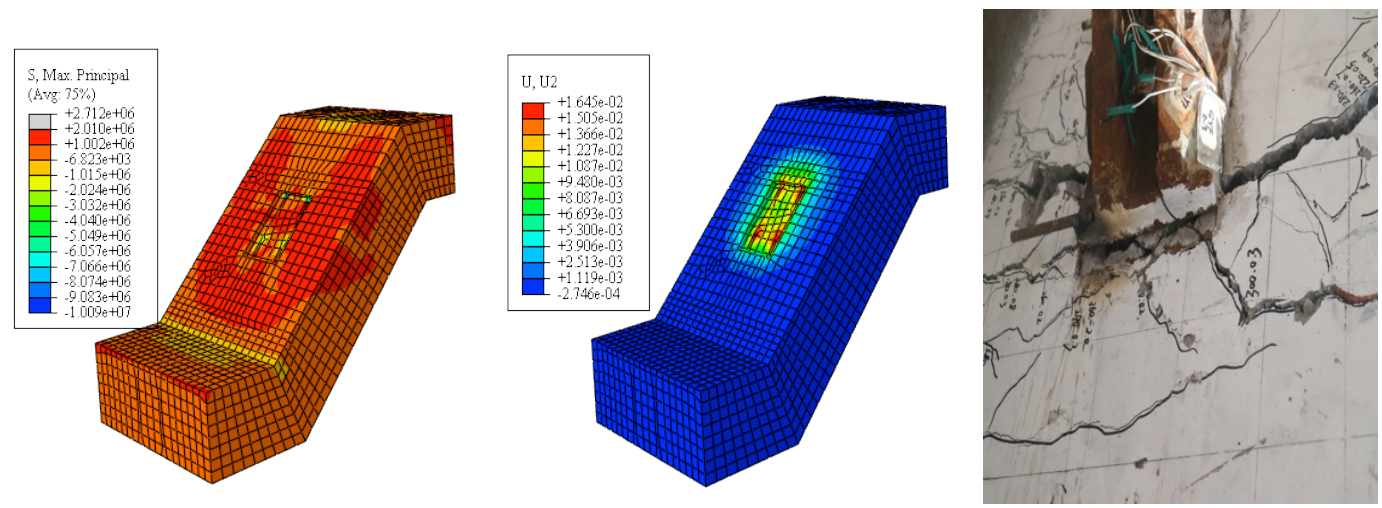

Fig.8. Comparative analysis diagrams for specimen SJ204025N
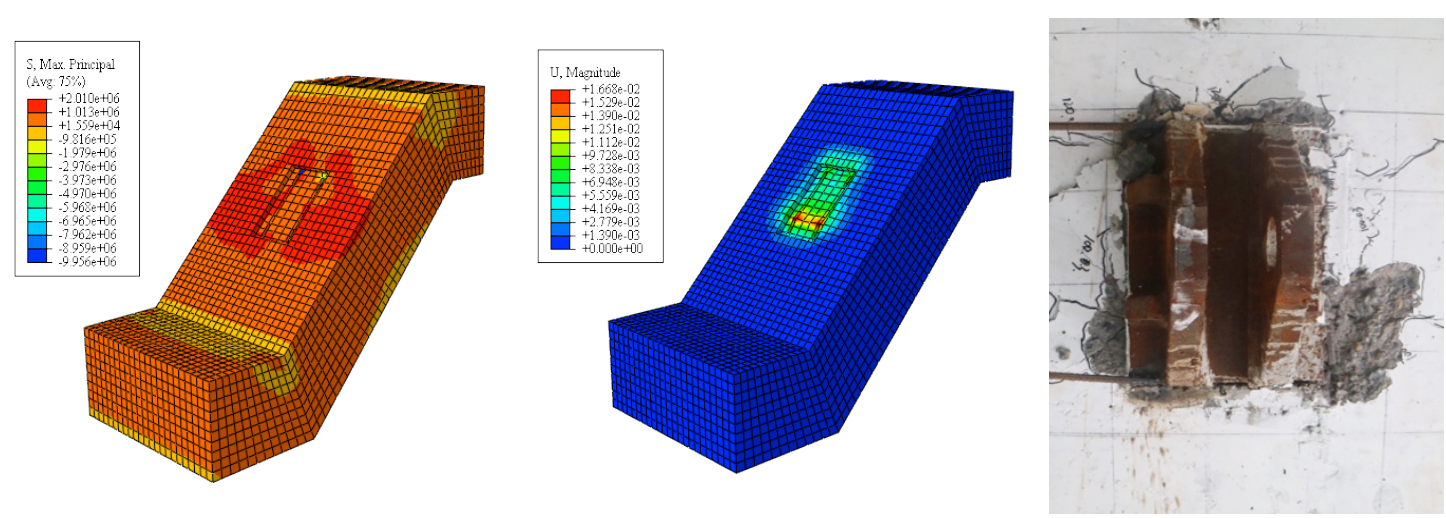

Fig. 9. Comparative analysis diagrams for specimen SJ165000N

Table. 4. Comparison of specimen ultimate capacity

\begin{tabular}{c|c|c|r|r|r}
\hline \multicolumn{2}{l|}{ Specimen no. } & Damage pattern & Simulation value & Test value & Error rate \% \\
\hline 1 & SJ204025N & Shear wall damage & 421.3 & 463.3 \\
2 & SJ165000N & Embedded part pullout & 271.6 & 9.07 \\
3 & SJ165000Y & Shear wall damage & 324.5 & -5.85 \\
\hline
\end{tabular}

As shown in Table 4, the damage patterns from specimen simulation were the same as the experimental results. For specimen SJ165000N, the embedded parts slipped because of insufficient anchorage, whereas the rests were all shear wall damages. The ultimate capacity values from simulation and test were close, showing a maximum error of $9.38 \%$, and the simulation value was less than the test value. According to the analysis of error causes, the relative errors between the two were caused by a certain difference between the constitutive model and bond-slip constitutive model defined by finite element method from the real constitutive model of material, as well as the discreteness of the mechanical properties of concrete itself. The negative error of specimen SJ165000N may be due to the occurrence of slippage displacement of embedded parts. The finite element-based bonded slipping constitutive relation always exists during the loading process and continued to bear the pullout load. By contrast, during the test, the chemical adsorption function of anchor slabs and concrete failed once the slippage displacement of embedded part occurred, and the pullout load was borne only by the frictional and mechanical build-in forces. Thus, the test values were less than the simulation values, showing a difference of $-5.85 \%$. From the perspective of the overall force performance evaluation of embedded parts, such an error rate was still within an acceptable range, the test data were credible, and the numerical models were correct, which can be used for the parametric analysis of factors influencing the bearing capacity of embedded parts.

\subsection{Comparison of model calculations with test results}

The load-displacement data were extracted from the ABAQUS numerical simulations and compared with the experimental data to mutually verify the correctness and reliability of the data. The three specimens were crosscompared, as shown in Figs. 10-12.

As shown in Fig. 10, the specimen is a reinforced embedded part with no pegs on the end slab. The test and simulation values of ultimate capacity differed by $10.6 \%$, which is acceptable. The bearing capacity is always controlled by the strength of shear wall concrete because of the same damage pattern between the two. However, the two exhibited a large difference in the displacement curve. In the early loading stage, the elastic modulus of concrete defined in the simulation calculation can rather truly reflect its actual force state under the test loads because the concrete is still in the elastic stage without crack generation and the structural stiffness does not undergo significant change. The displacement curves of the two were well fitted and the slopes were basically identical. However, as the load continued to increase, cracks appeared, broadened, and increased, and the displacement curves shifted and enlarged gradually. In the later stage of loading, the test displacement value was markedly larger than the simulation value due to 
the continuously increasing crack width, which is approximately three times that of the simulation value when near the limit, showing a large error. Compared to the simulation curve, the test curve exhibited larger platform damage, stronger load sustainability, and better ductility. Nonetheless, from the perspective of the variation regularity of displacement, the two were basically identical in trends.

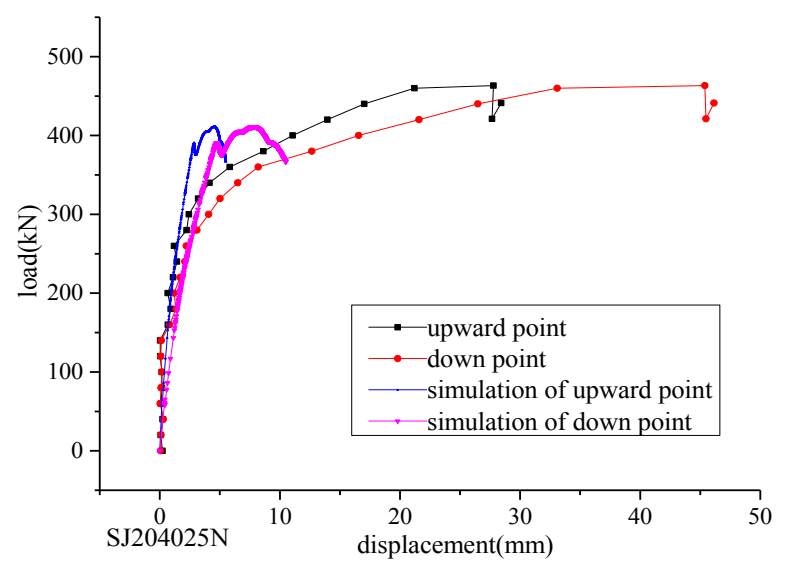

Fig. 10. Comparison of load-displacement curves for specimen SJ204025N

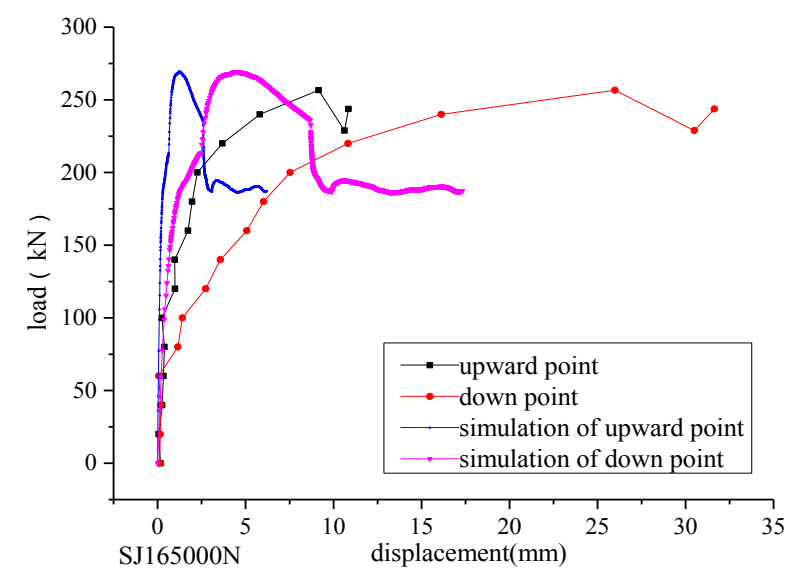

Fig.11. Comparison of load-displacement curves for specimen SJ165000N

As shown in Fig. 11, the load-displacement curves of specimen SJ165000N basically coincide in the early loading elastic stage, with only small difference in stiffness. However, with the increase of load, the concrete cracked, stiffness degraded, and test and simulation values of displacement showed a rapid difference, which ever enlarged. The cause of difference in displacement at the upper measuring point between the two was because the cracking discontinuity of concrete cannot be preferably simulated with the concrete constitutive model selected in the simulation calculation. Moreover, on the contact surface between the anchor slab and the concrete, the defined bonded slipping constitutive relation differed somewhat from the experimental one. Moreover, the discreteness of concrete material strength itself and the inhomogeneity of medium were the causes of such discrepancy. The simulation values of displacement at the upper and lower measuring points were basically the same, which was quite different from the test case. The effects of the shear deformation of concrete along the axial direction of shear wall, the cracking of concrete to the limit state, and the width of major crack on the increase in the displacement of embedded parts, which were not considered in the simulation calculation, were analyzed. The ultimate capacity of the two differed by $8.7 \%$, where the simulation value was greater than the test value, and the error was acceptable. In terms of the exploratory comparison of the deformation and damage trends of structure, the test and simulation were cross-compared, and the trends reflected in the data were correct and credible.

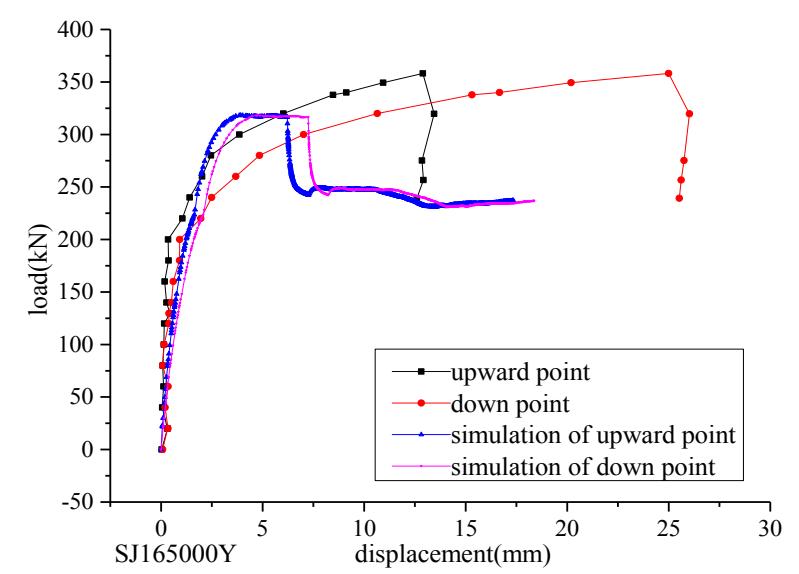

Fig.12. Comparison of load-displacement curves for specimen SJ165000Y

As shown in Fig. 12, the specimen SJ165000Y is an anchoring reinforced with pegs. In the ABAQUS finite element simulation, the anchoring reinforcing effect of pegs was realized by adding spring elements and defining the stiffness. The two types of values were rather close regarding the ultimate capacity, with a difference of $11.9 \%$, where the test value was higher than the simulation value. In the early loading stage, the two types of displacement values were relatively close, the curves were well fit, and the displacements of embedded parts at the upper and lower measuring points did not differ much. In the later loading period, the differences between the two values began to increase. The curve for simulation value rose basically along the initial slope to the damage platform of structure, the structure cracked, and the influence of stiffness degradation was small. For the test values, the curve gradually flattened out in the later loading stage, the displacement increased rapidly, and the difference between the embedded part displacements at the upper and lower edges also increased gradually, reflecting that the concrete cracking and the embedded part rotation around the geometric center were greatly influential to the displacement growth. The total displacement was nearly twice the simulation value. Clearly, the simulation value was accurate in calculating the bearing capacity, because the damage patterns of the two were basically identical, both of which are controlled by the strength of concrete. By contrast, the difference in displacement was rather large, mainly because the diffusion crack model incorporated in ABAQUS cannot well simulate the actual cracking pattern of concrete. In the later stage of loading, the cracks widened. Their intensive internal distribution greatly affected the pullout displacement of embedded parts, thus resulting in a large displacement difference. Compared with the SJ165000N without pegs, the simulation value of bearing capacity defined by the spring stiffness increased by $15.4 \%$, which reflected the contribution of pegs to the anchorage reinforcement. In addition, the bearing capacity must be calculated by using the simulation method of defining spring elements. 


\section{Conclusion}

To study the working mechanism of the attached to the wall joints of high-performance tower crane, the force performance of these joints was explored through scale model test and numerical simulation. The pullout test was conducted by setting the embedded parts of the scale model with different parameters, and the whole process of model test was numerically simulated by finite element method. The following conclusions could be drawn:

(1) The embedded parts undergo two types of damages depending on the installation form: pullout damage of parts due to incomplete anchoring and bending fracture damage of shear walls under sufficient anchoring. The difference in bearing capacity is large between the two types.

(2) The load-displacement curves of embedded parts show obvious two-stage variation. In the early loading stage, the curves can almost be fitted to a straight line, the displacements are very small, and the structures are within the linear elastic range. After continuance of loading and cracking, the stiffness degradation occurs, the slopes of curves decrease, and the displacement growth accelerates. The later the stage, the wider the crack distribution, and the severer the stiffness degradation. The embedded parts undergo combined deformation of the tension, flexural, and shear under the action of diagonal tension. The local rotation tendency of embedded parts around the geometric center results in the significantly less displacement and correspondingly smaller strain of the upper anchor slabs than the lower anchor slabs.
(3) Anchoring reinforcement has no obvious effect on the displacement. However, if the anchorage is not reinforced, then the embedded parts will be prone to slip and pullout damage and the anchorage stiffness will be small.

(4) The attached to the wall joints of tower cranes bear the compound stress effect of the tension, flexural, and shear, showing a complex local stress distribution. The possible damage patterns of the embedded parts include the cross-sectional area of the tensile strength of the anchor plate, weld connection of the anchor plate, overall punching damage considering the group anchorage effect, and bending damage of narrow limbs outside the wall, among others.

In this study, the force performance of the attached to the wall joints of high-performance jib crane was investigated. Through comparative analysis, the reliability of the static pullout test data and the rationality of the finite element models were mutually validated. The research results were further extended on the basis of the validated finite element models, which are of referential significance to the analysis of the force performance of such joints and of the working mechanism for the enhancement of the seismic resistance of the joints. However, considering the lack of actual on-site monitoring data of joint damage under forces, in the future research, the field monitoring data can be incorporated into the present finite element model for correction to allow more accurate understanding of the working mechanism of the attached to the wall joints of high-performance tower cranes.

This is an Open Access article distributed under the terms of the Creative Commons Attribution License

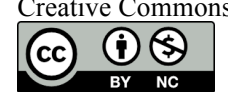

\section{References}

1. Tam Vivian W.Y., Fung, Ivan W.H.,'Tower crane safety in the construction industry: A Hong Kong study". Safety Science, 49(2), 2011, pp.208-215.

2. Sohn Hyo Won, Won Kee Hong, Lee, Donghoon, etal.,'Optimum Tower Crane Selection and Supporting Design Management". International Journal of Advanced Robotic Systems, 11(8),2014, doi:10.5772/58438.

3. Aviad Shapira F.ASCE, Beny Lyachin, "Identification and Analysis of Factors Affecting Safety on Construction Sites with Tower Cranes". Journal of Construction Engineering and Management, 135(1),2009,pp. 24-33.

4. Mara, T.G. ,"Effects of a construction tower crane on the wind loading of a high-rise building". Journal of Structural Engineering, 136(11), 2010, pp.1453-1460.

5. Li Yunling, Ai Bing, Li Bo," The damage cause of tower crane under earthquake action and the status of dynamic analysis". Special Structures, 28(2), 2011,pp.66-68.

6. Shen Tong, Yan Weiming, Zhou Daxing, etal., “ TMD Control and Analysis of Cranes under Earthquake". Technology for earthquake disaster prevention, 12(2),2017,pp.276-87.

7. Şahin Yavuz, Levent Malgaca, Hira Karagülle," Analysis of active vibration control of multi-degree-of-freedom flexible systems by Newmark method". Simulation Modelling Practice and Theory, 69, 2016,pp.136-148.

8. Lee Chijoo, Lee Ghang, Park Suyeul, Cho Joonbeom, ” Analysis of field applicability of the rotation-controllable tower-crane hook block". Automation in Construction, 21(1), 2012, pp.81-88.
9. Ai, Bing, Yang, Jia Lin, Pei Zeng Zhuang,"Seismic response analysis of tower crane in consideration of the building-crane interaction". Applied Mechanics and Materials, Advances in Civil and Industrial Engineering, 353-354, 2013,pp.1981-1985.

10. Huang Li Jeng, Syu HongJie," Seismic Response Analysis of Tower Crane Using SAP2000”. Procedia Engineering ,79, 2014,513-522.

11. Alamoreanu Mircea, Vasilescu Andrei," Behavior of Tower Cranes under Seismic Actions".Mechanical Engineering, 72(2), 2010,pp.55-64.

12. Li J R, Song B, Cui J Y.," Dynamic interaction behavior between jumbo container crane and pile-supported wharf under near field and far-field ground motions". Journal of Engineering Science and Technology Review, 1(9), 2016,pp.124-130.

13. Shapira, Aviad, Elbaz, Avihu," Tower crane cycle times: Case study of remote-control versus cab-control operation". Journal of Construction Engineering and Management, 140(12), 2014. 05014010 .

14. Dong Q., Xu, G.N., Ren, H.L., and Wang, A.H., "Fatigue remaining life estimation for remanufacturing truck crane Jib structure based on random load spectrum". Fatigue and Fracture of Engineering Materials and Structures, 40(5), 2017,pp.706-731.

15. Hazriq Izzuan Jaafara, Z. Mohamedb, J.J. Jamianb, etal.," Dynamic Behaviour of a Nonlinear Gantry Crane System". Procedia Technology,11 ,2013,pp. 419-425.

16. Feng Ju, Yoo Sang Choo, F.ASCE.," Dynamic Analysis of Tower Cranes".Journal of Engineering Mechanics, 131(1),2005,pp.88-96. 